safely adopted. Meanwhile, it may be fair to suppose that vaccination can light $u_{1}$, a dormant infection such as low grade septicaemia.

4. The comparative immunity of infants to complications after vacrination would appear to be due to the fact that they are hardly likely to be harbouring such an infection. As for the still not uicommon gross infection of the vaccination site, young infants are obviously mable to set up such a condition, since they cannot scrateh their own arms.

RePFrexces.

Diamond: Areh. Nourat. and l'sych., vol. $x x, 111$, p. 524; Grinker and Stone: Ibid., p. 244.

z Turnbull and MeIntosh: Jonrn. Erper. I'ath., 1926, vol. vii, p. 181.

Troup and Weston IIurst: laucet, 1930, i, 566

\section{PRIMARY CARCINOMA OF THE APPENDIX.}

J. W. M. H. PHILIIPS, D.M., M.Ch.Oxon, F.R.C.S.Fd., HONORARY SURGEON, PORT TALBOT HOSPITAL;

DONAID H. ISAAC, M.R.C.S., L.R.C.P.

Minicint disease of the appendix is of some special interest, not only by reason of the popular idea as to its rarity, but also because of the histological and other

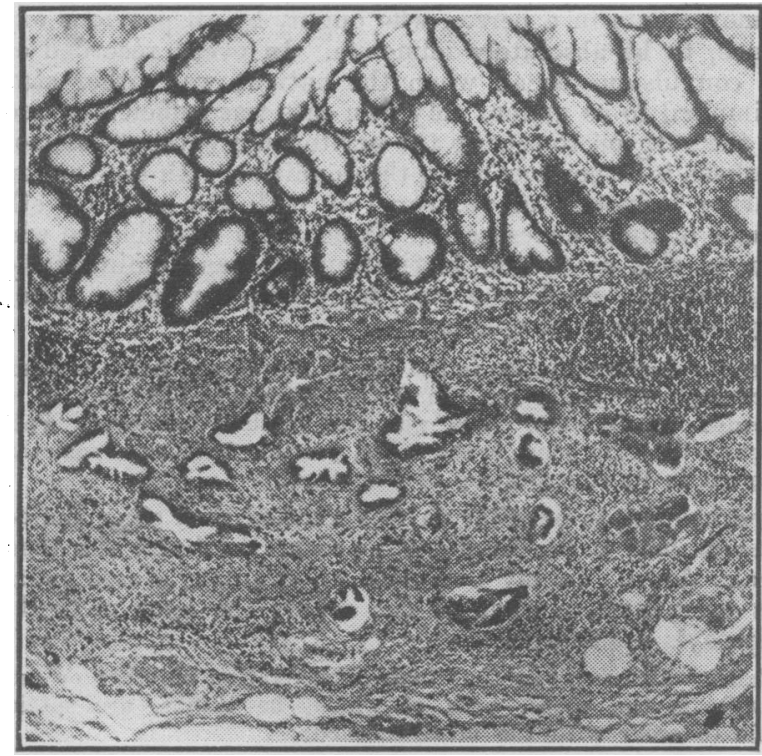

Fig. 1.-Growth in the appendix.

problems which are concerned. It may therefore be worth while recording a case which illustrates some points of importance in these respects.

A multipara, aged 5t, who had lost one sister from carcinoma of the cervix, but whose personal and family history was devoid of túbercle, sought belated advice for colicky pains and distension, variable in relation to meals; the condition was becoming more constant, and ncrer exhibited periodicity. She gave a history of previous indigestion over a period of some years, sometimes interspersed with fairly severe and prolonged colic. Medical advice she eschewed on the representations of officious friends, who feared for her the "way of the knife." Her symptoms gradually became more severe, and the supervention of some wasting and occasional bouts of romiting made a consultation imperative. She was constipated; she never at any time suffered from alternating diarrhoea, nor was there ever any declared blood in her stools.

Physicul Framination.-The woman was pale and cachectic, and there was loss of dermal clasticity. Her regular pulse of 90 was of a sinister softness in quality. No chrst lesion was detectable. The upper abdomen showed a little fullness, and peristalsis could just faintly be disccrned. Liver dullness was normal, and no splenic enlargement could be made out. It was observed that while no caput medusae was in evidence, the protruding umbilicus, quite small, had a nodular cartilaginous foel. In the right iliac fossa there was an indefinite hard mass, freely movable through a small arc of a circle centred at the umbilicus, though not along its radius. The swelling, about the size of an orange, presented no graded upward margin, as in ileo-caecal tuherculosis, and it appeared to be of uniform ensistency. Pelvic examination shed no further light, nor was there any enlargemeni of the ovaries. Owing to temporary disorganizalion of piant, and the comparative urgency of the casc, radiography was dispensed with. The diaguosis, indeed, seemed clearly to be adeno-carcinoma of the caecum, or possibly the formative type of ileo-caecal tuberculosiz, either alternative offering a reasonable hope from surgical intervention.

Oprration.-A low paramedian coeliotomy was performed, and a lithle free fluid escaped. The most striking feature was a hardened nodular cake-like mass, consisting of omentum, obviously infiltrated with growth, and receiving at the umbilious a small but firm attachment to the anterior abrlominal wall. From this region it was carried downwards to adhere to, to cross superficially, and to kink, almost to the occlusion of its lumen, the lower four inches of the ileum. From here it proceeded to the appendix, which in part it clothed, and to which it firmly, but sparingly adhered. The appendix, twisted upon itself, presented three ovoid swellings, cartilaginous to the feel, measuring 1 by $1.5 \mathrm{~cm}$., serially arranged in apposition like a string of beads. The mesentery of the appendix was short, thick, and infiltrater with excess of fat. The appendicular lymph nodes were not enlarged, nor indeed was there any evidence anywhere in the abdomen of glandular involvement, save in the portal fissure, and here it formed a noteworthy feature. The serous coat of the appendix was much thickened, but retained its sheen, and was typically pearly. Macroscopically there was no involvement of the caecum, which was connected to the oval masses by a shor length of apparently normal appendix. Systematic and meticulou

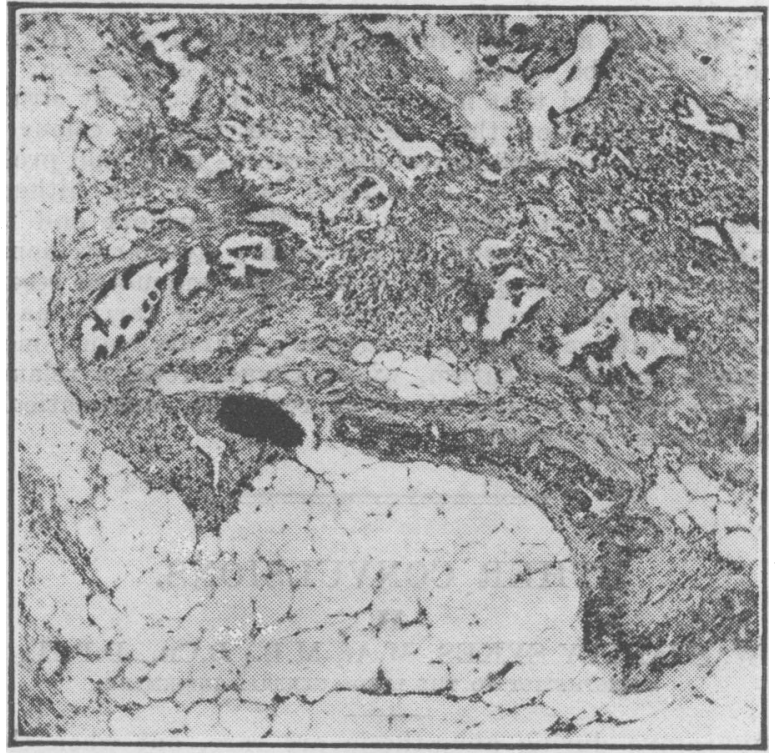

FIG. 2.-Growth in the great omentum.

scrutiny excluded all other of the abdominal contents than tho appendix as the fons ct origo of the primary neoplasm. The precarious state of the patient, no less than the infiltration of the whole of the great omentum and the involvement of the lymph nodes in the portal fissure (a seeming anomaly), precluded furtlier surgical procedure than the removal, scrundum artcm, of the appendix and the freeing from its omental embartassment of the involved segment of the ileum.

Morbid Histology.-For the following palloological report on the condition of the appendix and the omentum we are indebled to Dr. Arthur Sladden, director of pathology at Swansea Hospital : "Sections of the appendix show the presence of a growth of the adeno-carcinomatous type infiltrating the whole of the submucons coat. The cells are regular, uniform, and cubical The portion of omentum submitted for examination exhibits diffuse infiltration with a neoplasm whose cells are of the same gencral type.'

The appendicular neoplasm is generally looked upon as a rare condition. The Mayo Clinic papers, however, place its incidence at 1 in 225 of all cases of appendicitis nccessitating operation. Although this figure would seem a littlo pessimistic, and perhaps not quite in arcord with common experience, the growth cannot be so uncommon as one might suppose. Many more examples would undoubtedly be revealed if all appendices removed were submitted to histological investigation.

Much controversy has centred in the phylogeny of tho yellow tumour of the appendix, with its characteristic ring 
of infiltration of the submucosa. Some, notably Aschoff, relegate it to the angioblastomas. Its colls are so ordered, fiattened, and clear that this conclusion is tempting. Other histologists, interpreting these cell appearances as results of low grade anaplasia and tissue pressure, regard the growth as carcinomatous, but of such low malignancy as never to occasion metastases, nor, in the words of Boyd, " to cause the death of a patient."

This case shows that under unfarourable conditions, of which the time factor is one, an appendicular neoplasm can at least infiltrate, and has encompassed the dcath of a patient. It is evident that this growth, or its probable predecessor, chronic appendicitis, had been troubling our patient for years, and, unfortunately for her, not very severely. Indeed, but for the fortuitous offices of her overzealous "policeman of the abdomen," the great omentum, she might yet be harbouring a neoplasm of the appendix, still " henign," with little to show for it beyond dyspepsia.

In 90 per cent. of all cases the incidence of the morbid process is at the tip of the appendix. More fortunate, howerer, is the lot of the 10 per cent. in whom it is found (incidentally and accidentally) in the proximal part, for in this region the early narrowing of the lumen leads to appendicitis of the obstructive type, calling for immediats intervention and its removal out of harm's way, as in the series of cases recorded by Wilkie.

It may be argued that our case is in no way comparable with the typical appendicular neoplasm; that, indeed, it bears the stamp of an evident adeno-carcinoma such as may be found anywhere in the alimentary tract. If that is so, it must be unique and all the more interesting. It must be admitted that macrosdopically it is only by straining the imagination that we could describe its colour as yellow. From its histological appearances we should prefer to suggest that it is transitional between the hitherto described "benign carcinoma" of the appendix and the frankly malignant group of alimentary adeno-carcinomas in general. Microscopically, it bears an undoubted resemblance genetically to the so-called "benign carcinoma"; but it has infiltrated, and it certainly exhibits rather more anaplasia in the omentum, where tissue pressure relaxes, and the cell, ever impatient of restraint, automatically becomes more wayward.

\section{ETHER CONVULSIONS.}

\section{BY}

W. STANley SyKes, M.A., M.B., B.Ch., D.P.H., ANAESTHETIST TO THE LEEDS GENERAL INFIRMARY.

Convussions during anaesthesia are rare, but when they occur they are both dramatic and dangerous. The tragically sudden death of one of my own patients aroused in me a desire to know more about this subject, and led me to make the following collection of existing theories. My own case corresponds very closely indeed with those described by Wilson', and may be taken as typical.

The patient was a young adult, aged 28 , with a septic lesion (pyosalpinx). The induction was uneventful, and the anaesthesia proceeded without incident for thirty to forty minutes. Suddenly, withoul previous cyanosis or warning of any kind, twitchings of the face appeared, which spread to the arms and legs until the whole body was in clonic convulsions and the patient had to be held on the table. There was no primary failure of the heart or respiration. Cyanosis did not occur until convulsions had been in progress some time, and was only slight. Death took place before it was well marked. (The death rate is nearly 25 per cent. in the recorded cases. It must be clearly understood that the convulsions come on when the patient is properly under.

Most of the published accounts regard the convulsions as an entirely new phenomenon, the first crop of cases occurring in 19ட5-26. One observer, ${ }^{2}$ however, saw five cases between 1913 and 1925, so that this is not strictly true. Another case is on record dating from 1922. It is certain, however, that they are much more common now than formerly. It may be argued that they occurred before, but passed unnoticed because of their rarity, and it is true that even now they are very rare. 'MrCardie ${ }^{3}$ in thirty-two year's' anaesthetic practice never saw a case at all, and many other anaesthetists of vast experience are in a similar position. I have seen one case in nearly 5,000 administrations. On the other hand, it is the rarities which get described in the journals, and ether convulsions are so umprecedented and so fatal that it is justifiab!e to assume their incidence before 1525 to be infinitesimal, or some of them would surely have been reported. Delared chloroform poisoning is also extrenely rare, and not nearly so evidently connected with anaesthesia as these convulsions sire, but in spite of this it has been known to the textbooks for decardes.

\section{Theories of causution.}

The obscurity of the subject is well illustrated by the number of theories purporting to explain it.

Muskens 4 states: "In my book Epilepsy. I have been able to assemble evidence . . . to prove that the period of transition from unconsciousness to consciousness, as in waking from sleep, is the period par excellence for the occurrence of epileptic phenomena. Further, a latent tendency to epileptic manifestations is frequently betrayed for the first time at this period.... The period of transition from unconsciousness induced by a narcotic $\ldots$ is associated with the same tendency. ... The evidence afforded seems to me to suggest the question : Why are epileptic manifestations so comparatively rarely seen in persons emerging from narcosis?"

This hypothesis aiters the facts to fit the theory. Ether convulsions begin during the surgical stage of anaesthesia, and not during the emergence from narcosis. Their most startling and characteristic feature is the sudden occurrence of movements in a person who ought, by all previous experience, to be absolutely immobile. In every recorded case the convulsions began when the patient was either stated or implied to be under. My own case was sufficiently under for the surgeon to sew up the peritoneum without comment. Muskens is either confusing the condition with true epilepsy (during induction or recovery) or with the harmless ether tremor of light anaesthesia. It bear's no resemblance whatever to this or to the jactitations of gas administration. Incidentally, most reports, including my own, give a negative history of epilepsy.

Fairlie $^{5}$ draws attention to the use of the Pinson bomb in a large percentage of the cases. In 11 of Pinson's $15,{ }^{6}$ and in one recorded by Dickson, ${ }^{7}$ this was the method employed. Fairlie suggests that the bomb is the cause, possibly because of something inherent in its superheating of the elher.

Superheating is peculiar to this method, but since the convulsions may occur in the absence of the bomb the theory breaks down. In my own case an ordinary closed inhaler was used, and in some of the others the open method or Shipway's apparatus.

Fairlie $^{8}$ also suggests that high concentration of ether or excess of $\mathrm{CO}_{2}$ is the cause, both of which, he thinks, are specially liable to occur with the bomb method.

But high concentration of ether and excess of $\mathrm{CO}_{2}$ can also be obtaned by other methods with apparent impunity. In the early years of the century ether was given exclusively in closed inhalers to patients who had received no preliminary medication whaterer (the resulting cyanosis (avsing ether to be disliked hy the suigeons of that generation) and convulsions did not occur. Fxtreme cyanosis is of ten seen during inexpert nitrous oxide administration, but it produces nothing more serious than the jactitations of the textbooks, which cease as soon as air or oxygen is givon. Again, true ether convulsions are not ushered in by cranosis.

Hewer ${ }^{9}$ brings forward the additional argument that convulsions have occurred during endotracheal administration, when the $\mathrm{CO}_{2}$ content of the alveolar air is less than normal. Pinson ${ }^{10}$ blames high concentration of $\mathrm{CO}_{2}$, while denying that the bomb is a factor in its production. The same objections apply as in the preceding paragraph.

Hornabrook ${ }^{11}$ holds that ether is not to blame, but that the atropine given before anaesthesia is the cause, a dose safe enough in itself being an overdose to a patient under ether.

It is true that atropine in poisonous amounts will cause convulsions, but it is difficult to believe that routine doses can have this effect, when it is common knowledge that they are insufficient to produce the other manifestation of atropinism-pupillary dilatation. If they did, convulsions would be very common and the synergism would be well 